\title{
Effect of Oxidative Stress on Occurrence of Subclinical Mastitis in Uterine Infected Murrah Buffaloes
}

\author{
Prachurya Biswal $^{1^{*}}$ and S. S. Lathwal ${ }^{2}$ \\ ${ }^{1}$ LPM section, ICAR-IVRI, Izatnagar, Bareilly, India \\ ${ }^{2}$ LPM section, ICAR-NDRI, Karnal, India \\ *Corresponding author
}

\section{A B S T R A C T}

Keywords

Oxidative stress,

Uterine fluid

scoring, SCC

(Somatic cell count)

Article Info

Accepted:

07 November 2019

Available Online:

10 December 2019
The experiment was carried out to study about the occurrence of subclinical mastitis during oxidative stress period in relation to uterine infection in Murrah buffaloes $(n=24)$. Uterine fluid was collected from day +7 to day +35 by help of a blue sheath and animals were divided into two groups based on uterine fluid scoring i.e. healthy and uterine infected groups. Then milk sample was collected from day +7 to day +35 in both the species and for detection of mastitis SCC (Somatic cell count), CMT (California mastitis test) and EC (Electrical conductivity) tests were conducted. Somatic cell count was higher in uterine infected group than the healthy group of buffaloes, however, difference was non-significant $(\mathrm{P}>0.05)$. When compared across the days, no significant difference $(\mathrm{P}>0.05)$ was observed in both healthy and uterine infected Murrah buffaloes. Kappa analysis revealed a kappa value of 0.424 suggesting moderate agreement with gold standard for California mastitis test and 0.713 for electrical conductivity test suggesting substantial agreement with the gold standard test.

\section{Introduction}

Transition period is the most critical period during which dairy animals are at a higher risk for oxidative stress and various infectious diseases like mastitis, clinical endometritis, metritis, pyometra etc. Presence of high progesterone (Tizard, 1991) during gestation period and high cortisol around parturition
(Magnusson and Fossum, 1992) leads to immune suppression in dairy animals. It is reported that during peripartum period there is enhanced production of reactive oxygen and nitrogen species (ROS and RNS)(Rizzo et al., 2013) and excess generation of ROS and RNS results damage of macromolecules like proteins, lipids and DNA (Trevisan et al., 2001) and it is controlled by cellular 
antioxidant defence systems. Oxidative stress results when ROS are produced faster than their neutralization by antioxidant mechanisms (Trevisan et al., 2001). Oxidative stress during the peripartum period is a major threat and the incidence of health problems is clearly a huge complicating factor for subsequent reproductive performance (Ferguson, 1996).In dairy animals, oxidative stress may cause mastitis and reproductive disorders during puerperum(Turk et al., 2012) which may directly influence their productivity by reducing milk production (Lykkesfeldt and Svendsen, 2007). Bovine mastitis is one of the most significant production diseases in dairy animals which is directly or indirectly affect the farmers and ultimately affect the economy of the country. On the other hand, mastitis is a global problem as it unfavourably affects animal health status, consistency, and quality of milk and economics of milk production (Sharma et al., 2011). Approximately $70 \%$ of these costs are connected with decline in milk production, 9\% milk thrown away after treatment, $7 \%$ cost of veterinary charges and $14 \%$ premature culling (Sharma et al., 2011). SCC is a useful predictor of intramammary infection (IMI), and therefore, an important component of milk in the assessment of aspects of quality, hygiene and mastitis control. The CMT provides a cheap and reliable indirect method to estimate SCC of individual quarters (Schalm et al., 1971). The CMT is a rapid and inexpensive test to indirectly determine the somatic cell concentration in milk (Midleton et al., 2004) and is a practical, easy method for demonstrating intramamary health by testing milk samples on-farm (Dingwell et al., 2003). Electrical conductivity (EC) measures the ability of a solution to conduct an electric current between two electrodes, and it is measured in millisiemens $(\mathrm{mS})$. EC has a potential for increasing the accuracy of the selection criteria. Studies about the incidence of subclinical mastitis in uterine infected
Murrah buffaloes during oxidative stress is scare hence keeping this in view the current study focuses on the occurrence of subclinical mastitis during the peripartum period in Murrah buffaloes.

\section{Materials and Methods}

The present research was conducted at Livestock Research Centre, National Dairy Research Institute (NDRI), Karnal, Haryana. In the present study 24 Murrah buffaloes were selected at peripartum period (10 days before expected date of calving to 35 days after calving). The milk sample from individual animals was collected in $50 \mathrm{ml}$ sterilized milk sampling bottles on $7^{\text {th }}, 14^{\text {th }}, 21^{\text {th }}$ and $35^{\text {th }}$ day after calving after proper disinfection of teat surface with $70 \%$ ethyl alcohol and discarding few streams of milk. Immediately after collection, the tubes were transported to the laboratory in ice box for further processing.

Uterine fluid was collected using a blue sheath (IMV technology, France) fitted in Universal AI gun by inserting it into vagina till it reaches the uterine horn guided by per rectal palpation. Uterine fluid was aspirated by gently pulling the plunger to create a negative pressure. Then the fluid was collected in a $15 \mathrm{ml}$ sterile falcon tube for further analysis.

\section{Uterine fluid scoring}

Scoring was done as the method described by Sheldon et al., 2009. Briefly buffaloes with fetid, watery uterine discharge having necrotic debris and presence of systemic illness(dullness, pyrexia, prostration) within 710 days postpartum was diagnosed as puerperal metritis. If within 21days of calving uterine discharge detectable at vagina was purulent in nature associated with enlarged uterus but not systemically ill was classified as clinical metritis. If discharge was purulent and mucopurulent in nature in $3 \mathrm{wk}$ or more than 
that it was classified as clinical endometritis. Buffaloes which had undergone normal puerperum without any postpartum complications were classified as healthy animals.

\section{California mastitis test}

The reagent used for CMT consists of an anionic surface active reagent and the indicator dye.

A plastic paddle was used having 4 separate wells. Milk from each quarter was poured in separate well. Equal volume of milk was mixed with CMT reagent with 1:1000 dilution of 3\% sodium lauryl sulphate and bromocresol (Delaval, Cardik, UK) and then the paddle was rotated in clockwise and anticlockwise manner for $10 \mathrm{sec}$. any change in colour or gel formation were interpreted.

Depending upon the viscosity of gel formation score was assigned from 1-5. Score 1 was considered as healthy where as score >1was considered as subclinical infection.

\section{Somatic cell count of milk}

Ekomilk scanner (digital somatic cell counter) was used for somatic cell count of milk. After washing the flask with $15 \mathrm{ml}$ distilled water $10 \mathrm{ml} \mathrm{milk}$ is poured in the flask and $5 \mathrm{ml}$ ekoprim solution is added to it. After that flask was shook automatically and reading was noted as displayed on screen.

\section{Electrical conductivity of milk}

Electrical conductivity meter (Orion 4-Star) was used for determination of Electrical conductivity of milk. $0.1 \mathrm{~N} \mathrm{KCl}$ was used as standard. Electrode was washed with normal saline before use and wiped with tissue paper to make it dry. After that it was dipped in milk sample and reading was noted.

\section{Statistical analysis}

Descriptive statistics were calculated for milk parameters in case of both healthy and uterine infected group and the results were expressed as mean $\pm \mathrm{SE}$. Within group comparisons were performed using independent sample $\mathrm{T}$ test. One way ANOVA was used to compare between groups. Group wise multiple comparisons were performed using Tukey's post hoc test. The difference of means was considered significant when the probability $(\mathrm{P}$ value) was <0.05. All the analysis was performed using IBM SPSS Statistics 22, Prism.

\section{Results and Discussion}

Based on the uterine discharge scoring and per rectal examination, Murrah buffaloes were classified into healthy and uterine infected groups. The healthy group consisted of buffaloes that had undergone normal puerperium without development of uterine infection. Animals with mucopurulent or purulent or fetid uterine discharge during postpartum period i.e. up to day 35 postpartum with or without systemic signs were classified as uterine infected animals. Out of total 24 animals 11 were found healthy and 13 animals developed uterine infection.

Results of California mastitis test shows significantly higher CMT score on day 7 between healthy and uterine infected Murrah buffaloes. When compared across the days there was significantly higher score on day 7 compared with all other days in uterine infected buffaloes whereas, no significant difference was observed across days in healthy buffaloes.

Higher score of CMT in uterine infected group shows direct association of subclinical mastitis and uterine infection. These results were in close proximity with Bacha and Regassa 
(2010). Somatic cells (Mean \pm SEM) in milk samples were higher in uterine infected buffaloes than the healthy Murrah buffaloes. However, difference was not significant ( $\mathrm{P}>0.05)$. When compared across the days, no significant difference $(\mathrm{P}>0.05)$ was observed in both healthy and uterine infected Murrah buffaloes. However, highest somatic cell count was observed on days +7 as compared to other days in both species. The increase in SCC during infection might be due to the fact that bacterial invasion to mammary glands attracts circulating PMN which in addition to the dead and sloughed off mammary epithelial cells leads to high somatic cell counts in the milk (Viguier et al., 2009). However, differences in CMT or SCC scores could also be associated with other factors such as age of cows and environmental factors (Harmon, 1994). Similar results were found in our study (Table 1).

Table.1 CMT, SCC and EC in milk of both healthy and uterine infected Murrah buffaloes during peripartum period

\begin{tabular}{|c|c|c|c|c|}
\hline Groups & Day 7 & Day 14 & Day 21 & Day 35 \\
\hline \multicolumn{5}{|c|}{ California mastitis test(CMT) scoring } \\
\hline Healthy buffaloes & $1 \pm 0^{\mathrm{A}}$ & $1 \pm 0$ & $1 \pm 0$ & $1 \pm 0$ \\
\hline $\begin{array}{c}\text { Uterine Infected } \\
\text { buffaloes }\end{array}$ & $1.46 \pm 0.13^{\mathrm{Ba}}$ & $1.2 \pm 0.10^{\mathrm{b}}$ & $1 \pm 0^{\mathrm{b}}$ & $1 \pm 0^{\mathrm{b}}$ \\
\hline \multicolumn{5}{|c|}{ Somatic cell count(SCC) in milk $\left(\mathbf{n \times 1 0 ^ { 5 }} / \mathbf{m l}\right)$} \\
\hline Healthy buffaloes & $1.14 \pm 0.25$ & $0.78 \pm 0.03$ & $0.74 \pm 0.03$ & $0.70 \pm 0.00$ \\
\hline $\begin{array}{c}\text { Uterine Infected } \\
\text { buffaloes }\end{array}$ & $1.84 \pm 0.32$ & $1.15 \pm 0.19$ & $1.01 \pm 0.15$ & $0.91 \pm 0.11$ \\
\hline \multicolumn{5}{|c|}{ Electrical conductivity test in milk (mS/cm) } \\
\hline Healthy buffaloes & $3.53^{\mathrm{a}} \pm 0.22$ & $3.24^{\mathrm{ab}} \pm 0.19$ & $3.03^{\mathrm{ab}} \pm 0.16$ & $2.69^{\mathrm{b}} \pm 0.13$ \\
\hline $\begin{array}{c}\text { Uterine Infected } \\
\text { buffaloes }\end{array}$ & $3.60 \pm 0.20$ & $3.33 \pm 0.17$ & $3.22 \pm 0.13$ & $3.03 \pm 0.14$ \\
\hline
\end{tabular}

Means bearing different superscripts (A,B,C,D) in column and superscripts (a,b,c,d) in row differs significantly $(\mathrm{P}<0.05)$

Comparisons between CMT, SCC and EC taking CMT as gold standard

There was no significant difference in the electrical conductivity of milk between the groups of buffaloes. When comparison was made across the days the electrical conductivity was higher on day +7 when compared with day 35 in healthy buffaloes whereas, no significant difference observed across days in uterine infected buffaloes. However, the conductivity remained higher throughout the study period. Our result is similar to the result of Norberg et al., (2004) which shows that EC of milk from cows affected by mastitis (both clinically and subclinically) is higher than EC of milk from healthy cows (not affected by mastitis). Kappa analysis was performed to understand the efficacy of different tests used for detection of mastitis. California mastitis test was considered as gold standard test and compared with somatic cell count and California mastitis test. The analysis revealed a kappa value of 0.424 for somatic cell count suggesting moderate agreement with and 0.713 for electrical conductivity test suggesting substantial agreement with the gold standard test. CMT, SCC, and EC observed to be higher in uterine infected animals than the healthy animals. The CMT provides a cheap 
and reliable indirect method to estimate SCC of individual quarters (Schalm et al., 1971). CMT is considered as the oldest gold standard cow-side test to identify subclinical mastitis and positively associated with SCC (Viguier $e t$ al., 2009). A few studies reported the genetic variation of electrical conductivity exists it's correlation with mastitis is positive (Norberg et al., 2004). In the present study, CMT was considered as the gold standard test and compared with SCC and EC using kappa test. The kappa value revealed moderate agreement with SCC whereas; EC shows substantial agreement with CMT. However, these differences in CMT or SCC scores could be due to factors such as the age of cows, parity and environmental factors as reported by Harmon (1994).

From the above study it can be concluded that during transition period there is occurrence of infectious diseases like mastitis, uterine infections in dairy animals. Higher score of CMT, SCC and EC in uterine infected group shows direct association of subclinical mastitis and uterine infection.

\section{References}

Bacha, B. and Regassa, F.G., 2010. Subclinical endometritis in Zebu $\mathrm{x}$ Friesian crossbred dairy cows: its risk factors, association with subclinical mastitis and effect on reproductive performance. Tropical animal health and production, 42(3), pp.397-403.

Dingwell, R.T., Leslie, K.E., Schukken, Y.H., Sargeant, J.M. and Timms, L.L., 2003. Evaluation of the California mastitis test to detect an intramammary infection with a major pathogen in early lactation dairy cows. The Canadian Veterinary Journal,44(5), p.413.

Ferguson, J.D., 1996. Diet, production and reproduction in dairy cows. Animal
Feed Science and Technology, 59(1), pp.173-184.

Harmon, R. J. 1994. Physiology of mastitis and factors affecting somatic cell counts. J. Dairy Sci. 77: 2103-2112.

Lykkesfeldt, J. and Svendsen, O. (2007) Oxidants and antioxidants in disease: Oxidative stress in farm animals. Vet. J. 173: 502-511.

Magnusson, U. and Fossum, C., 1992. Effect of estradiol-17 beta treatment of gilts on blood mononuclear cell functions in vitro. American journal of veterinary research, 53(8), pp.1427-1430.

Middleton, J.R., Hardin, D., Steevens, B., Randle, R. and Tyler, J.W., 2004. Use of somatic cell counts and California mastitis test results from individual quarter milk samples to detect subclinical intramammary infection in dairy cattle from a herd with a high bulk tank somatic cell count. Journal of the American Veterinary Medical Association, 224(3), pp.419-423.

Norberg, E., Rogers, G.W., Goodling, R.C., Cooper, J.B., Madsen, P., 2004. Genetic parameters for test-day electrical conductivity

Rizzo, A., Roscino, M.T., Binetti, F.\& Sciorsci, R.L. 2012. Roles of reactive oxygen species in female reproduction. Reprod Domest Anim. 47:344-352.

Schalm, O. W., E. J. Carroll and N. C. Jain. 1971. Bovine Mmstitis. Lea \& Febiger, Philadelphia, USA.

Sharma, N., Singh, N.K. and Bhadwal, M.S., 2011. Relationship of somatic cell count and mastitis: An overview. Asian-Australasian Journal of Animal Sciences, 24(3), pp.429-438.

Sheldon, I.M., Cronin, J., Goetze, L., Donofrio, G. and Schuberth, H.J., 2009. Defining postpartum uterine disease and the mechanisms of infection and immunity in the female reproductive tract in cattle. Biology of 
reproduction, 81(6), pp.1025-1032.

Tizard, I., 1991. Use of immunomodulators as an aid to clinical management of feline leukemia virus-infected cats. Journal of the American Veterinary Medical Association (USA).

Trevisan, M., Browne, R., Ram, M., Muti, P., Freudenheim, J., Carosella, A. N. and Armstrong, D. 2001. Correlates of markers of oxidative status in the general population. Am. J. Epidemiol. 154:348-356.

Turk, R., Piras, C., Kovačić, M., Samardžija,
M., Ahmed, H., De Canio, M., Urbani, A., Meštrić, Z.F., Soggiu, A., Bonizzi, L. and Roncada, P., 2012. Proteomics of inflammatory and oxidative stress response in cows with subclinical and clinical mastitis. Journal of proteomics, 75(14), pp.4412-4428.

Viguier, C., Arora, S., Gilmartin, N., Welbeck, K. and O'Kennedy, R., 2009. Mastitis detection: current trends and future perspectives. Trends in biotechnology, 27(8), pp.486-493.

\section{How to cite this article:}

Prachurya Biswal and Lathwal, S. S. 2019. Effect of Oxidative Stress on Occurrence of Subclinical Mastitis in Uterine Infected Murrah Buffaloes. Int.J.Curr.Microbiol.App.Sci. 8(12): 493-498. doi: https://doi.org/10.20546/ijcmas.2019.812.065 